\title{
Tuning IMS LD for Implementing a Collaborative Lifelong Learning Scenario
}

\author{
Davinia Hernández-Leo, Eloy D. Villasclaras-Fernández, Juan I. Asensio-Pérez, \\ Yannis A. Dimitriadis, Miguel L. Bote-Lorenzo, José A. Marcos-García \\ University of Valladolid, Spain \\ \{davher,evilfer@ulises., juaase,yannis,migbot,jamarcos@ulises.\}@tel.uva.es
}

\begin{abstract}
This paper describes an approach for modeling and implementing a collaborative learning situation, which is part of a real lifelong learning scenario in astronomy. We adopt and slightly adjust IMS Learning Design for computationally representing the script so that collaborative tools can be satisfactorily employed. We use Collage editor, which enables the re-use of general structures proposed by Collaborative Learning Flow Patterns, for authoring the script and Gridcole system for executing it. The paper also shows the log-files produced by the employed tools. The teacher can use these log-files to monitor the evolution of the process for evaluation and regulation purposes.
\end{abstract}

\section{Introduction}

The support of IMS Learning Design specification (LD) for describing collaborative learning scenarios is still a research topic. However, there are already some examples that analyse its possibilities $[3,6]$. We use LD to formalize Units of Learning (UoL) based on what we call CLFPs (Collaborative Learning Flow Patterns), which capture the essence of good practices when structuring collaborative learning situations [3]. Nevertheless, in order to achieve a satisfactory enactment of the designs we apply an extension of the LD service element that enables us to generally specify a collaborative tool, so that different instances of the tool will be available to different groups/roles.

Section 2 illustrates how a collaborative lifelong learning scenario in astronomy is modelled using LD (and the general groupservice description), and authored with Collage editor [4]. Gridcole system is able to interpret the resulting UoL and to provide accordingly the instances of collaborative tools [1], as shown in section 3. This section also discusses the possibilities of our approach regarding observations and traces. The paper finishes with the conclusions.

\section{Authoring the scenario}

The description of the collaborative lifelong learning scenario is shown in Table 1. It is a summary of the UoL that specifies the scenario, created using Collage editor. It consists on an adaptation of the wellknown Jigsaw CLFP, which Collage provides as a reusable LD template [4].

Table 1. Summary of the UoL (based on Jigsaw CLFP) created using Collage editor

\begin{tabular}{|c|c|c|c|c|}
\hline $\begin{array}{l}\text { JIGSAW } \\
\text { CLFP } \\
\text { PHASE }\end{array}$ & $\begin{array}{l}\text { GROUP/ } \\
\text { ROLE }\end{array}$ & ACTIVITY & ACTIVITY DESCRIPTION & RESOURCES \\
\hline \multirow[t]{2}{*}{$\begin{array}{l}\text { Indivi-dual } \\
\text { study }\end{array}$} & \begin{tabular}{|l|} 
Jigsaw \\
group
\end{tabular} & $\begin{array}{l}\text { Individual } \\
\text { study }\end{array}$ & \begin{tabular}{|l|} 
At the end of this game you \\
have to be able to classify \\
the planets regards to their \\
distance to the Sun (from the \\
nearest one to the most \\
distant). Extract planets' \\
properties from the \\
assigned expert interview. \\
(Team A members' \\
interview contains planets' \\
order and some properties \\
(without names) and team \\
B's interview informs about \\
planet's names and some \\
properties.)
\end{tabular} & $\begin{array}{l}\text { *expert__ } \\
\text { interview }\end{array}$ \\
\hline & \begin{tabular}{|l|} 
Teacher \\
\end{tabular} & \begin{tabular}{|l} 
Activity \\
control
\end{tabular} & $\begin{array}{l}\text { You have privileged access } \\
\text { to the expert interviews }\end{array}$ & $\begin{array}{l}\text { *expert_- } \\
\text { interview }\end{array}$ \\
\hline Subproblem & \begin{tabular}{|l|} 
Expert group \\
Teacher \\
\end{tabular} & npty! & Not & \\
\hline \multirow[t]{3}{*}{$\begin{array}{l}\text { Global } \\
\text { problem }\end{array}$} & \multirow[t]{2}{*}{$\begin{array}{l}\text { Jigsaw } \\
\text { group }\end{array}$} & \begin{tabular}{|l} 
Global \\
discussion
\end{tabular} & $\begin{array}{l}\text { Cooperate with the other } \\
\text { team using a forum to } \\
\text { exchange information. Each } \\
\text { team can use a chat to make } \\
\text { their member discuss. }\end{array}$ & $\begin{array}{l}\text { *forum } \\
\text { *chat } \\
\text { *expert_- } \\
\text { interview }\end{array}$ \\
\hline & & \begin{tabular}{|l|} 
Solution \\
proposal
\end{tabular} & $\begin{array}{l}\text { Fill in (individually) a } \\
\text { questionnaire about the } \\
\text { planet classification. }\end{array}$ & $\begin{array}{l}\text { *question- } \\
\text { naire }\end{array}$ \\
\hline & Teacher & \begin{tabular}{|l}
$\begin{array}{l}\text { Activity } \\
\text { control }\end{array}$ \\
\end{tabular} & $\begin{array}{l}\text { You have access to the } \\
\text { forum, and can participate to } \\
\text { discussions. You can also } \\
\text { add new clues in any expert } \\
\text { interview. You have to } \\
\text { nominate a winner according } \\
\text { to the questionnaires. }\end{array}$ & $\begin{array}{l}\text { *question- } \\
\text { naire } \\
\text { * chat } \\
\text { *expert_- } \\
\text { interview }\end{array}$ \\
\hline
\end{tabular}


It should be noticed that although the expert group phase of the Jigsaw CLFP is not strictly considered in this scenario (not visible), the corresponding expertgroup role must exist to differentiate between members of team A and team B. This is needed for providing the right expert interview and the specific chat room. We model both tools as groupservices. A different instance of these services will be available only to the members of a particular team (each team is an instance of the expert-group role, see created-new attribute of the LD role element [3]). Each instance of the groupservice that models the interviews (considered as a kind of shared repository) will be also available to the teacher, so that she can add new clues.

\section{Execution, observation and traces}

Gridcole [1], which is based on CopperCore [7], is capable of interpreting the UoL created using Collage. This CSCL system guides users through the flow of collaborative learning activities integrating the tools needed to support them. In this scenario (see Table 1) the selected collaborative tools are a chat, Synergeia [5] (a shared repository for the interviews and a forum) and Quest [2] (for the final questionnaires). Depending on the groups Gridcole provides a specific service instance, as it has been mentioned in the previous section. Figure 1 is a snapshot that shows Gridcole making available, to a student of team $\mathrm{A}$, the common forum for exchanging information with the other team and the particular chat room she can use to discuss with her team's members.

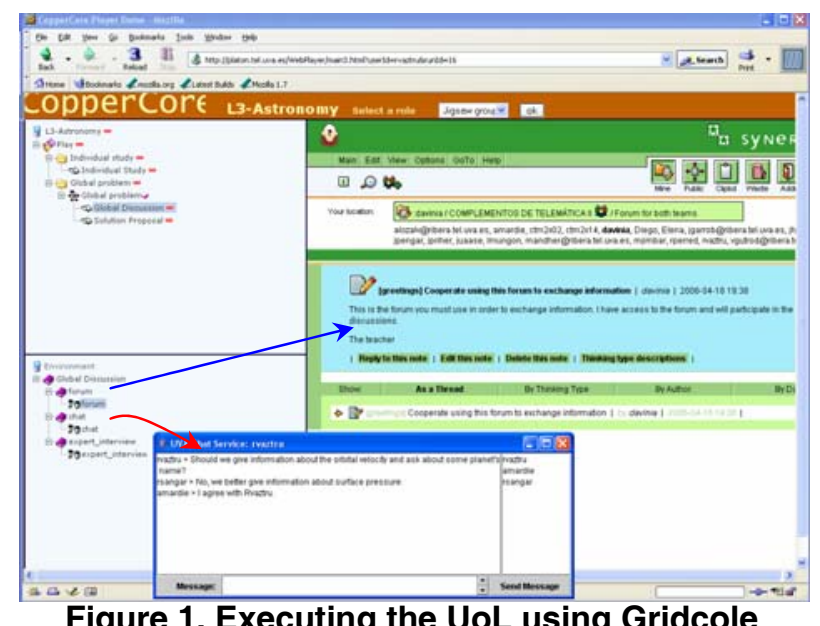

Figure 1. Executing the UoL using Gridcole

The discussions of each chat room are automatically stored in different files. Synergeia also provides logfiles collecting students' actions. The teacher can use this information for regulation purposes: participating during the execution of the UoL according to what she observes. The UoL may have been enriched by including LD properties for directly providing the logfiles to the teacher. These log-files can be also used to evaluate the learning process a posteriori: e.g. how students negotiate with their peers.

\section{Conclusions}

The implemented UoL is not properly a Jigsaw situation. However, it is inspired in its essence and can be easily created using Collage. Besides, it can be executed by Gridcole. Moreover, this UoL can be easily adapted for a different topic or learning situation. E.g. forming more teams or several (jigsaw) groups, i.e. mixing different members of team $\mathrm{A}$ and team B for cooperating in different forums. That would allow (for example) to study several negotiation strategies. In both cases it is only necessary to create more instances of the corresponding roles.

More information about the presented approach is available at http://gsic.tel.uva.es/collage/l3astronomy.

\section{References}

[1] Bote-Lorenzo, M. L., Vaquero-González, L. M., VegaGorgojo, G., Dimitriadis, Y., Asensio-Pérez, J. I., GómezSánchez, E., and Hernández-Leo, D., "A Tailorable collaborative learning system that combines OGSA grid services and IMS-LD scripting", $10^{\text {th }}$ International Workshop on Groupware, San Carlos, Costa Rica, 2004, pp. 305-321.

[2] Gómez, E., Rubia, B., Dimitriadis, Y., and Martínez, A., "Quest, A Telematic Tool for Automatic Management of Student Questionnaires in Educational Research", 2nd European Conference on Technology, Information, Education Citizenship, Barcelona, Spain, June 2002.

[3] Hernández-Leo, D., Asensio-Pérez, J.I., Dimitriadis, Y., Bote-Lorenzo, M.L., Jorrín-Abellán, I.M., and VillasclarasFernández, E.D., "Reusing IMS-LD formalized best practices in collaborative learning structuring", Advanced Technology for Learning, vol. 2, no. 4, Oct. 2005, pp. 223-232.

[4] Hernández-Leo, D., Villasclaras-Fernández, E.D., JorrínAbellán, I.M., Asensio-Pérez, J.I., Dimitriadis, Y., RuizRequies, I., and Rubia-Avi, B., "COLLAGE, a collaborative learning design editor based on patterns", Educational Technology and Society, vol. 9, no. 1, Jan. 2006, pp. 58-71.

[5] Synergeia Website, http://bscl.gmd.de, last visited: 2006. [6] Koper, R. and Burgos, D., "Developing advanced Units of Learning using IMS Learning Design level B", Advanced Technology for Learning, vol. 2, no. 4, Oct. 2005, pp. 252259.

[7] Martens, H. and Vogten, H. A reference implementation of a Learning Design Engine. In Rob, K. and Tattersall, C. Eds. Learning Design, a handbook on modelling and delivering networked education and training, Heidelberg: Springer-Verlag, 2005, pp. 91-108. 